\title{
Trypanosoma cruzi seroprevalence and associated risk factors in cancer patients from Southern Brazil
}

\author{
Luciane d'Avila Rosenthal[1], Cristiane Rios Petrarca ${ }^{[2]}$, Marilia Arndt Mesenburg ${ }^{[3]}$ \\ and Marcos Marreiro Villela ${ }^{[1]}$
}

\begin{abstract}
[1]. Programa de Pós-Graduação Stricto Sensu em Parasitologia, Departamento de Microbiologia e Parasitologia, Universidade Federal de Pelotas, Pelotas, Rio Grande do Sul, Brasil. [2]. Hospital Escola, Faculdade de Medicina, Universidade Federal de Pelotas, Pelotas, Rio Grande do Sul, Brasil. [3]. Programa de Pós Graduação em Epidemiologia, Universidade Federal de Pelotas, Pelotas, Rio Grande do Sul, Brasil.
\end{abstract}

\begin{abstract}
Introduction: The aim of this study was to investigate the prevalence of Chagas disease in patients treated at a Public Oncology Service in the City of Pelotas, Southern Brazil. Methods: This study included 200 individuals undergoing cancer treatment and involved the use of a questionnaire and venous blood collection for the detection of anti-Trypanosoma cruzi antibody. Results: The study found a $5 \%$ prevalence of patient seropositivity. Significant variables are presented and discussed in the article. Conclusions: Serological T. cruzi checks are recommended in cancer patients, especially individuals from endemic areas in Brazil and other Latin American countries.
\end{abstract}

Keywords: Cancer. Chagas disease. Trypanosoma cruzi.

Chagas disease (CD), also known as American trypanosomiasis, has great public health relevance and occurs throughout the Americas from the Southern United States to Southern Argentina and Chile. It is estimated that there are about 8 to 10 million people infected with Trypanosoma cruzi in Latin America alone, with 300,000 new cases every year, including two to three million patients with chronic complications of the disease ${ }^{(1)}$.

The clinical relevance of immunosuppression to CD development has increased in recent years ${ }^{(2)}$. In addition, the array of neoplastic diseases that cause immunosuppression has increased because of the expansion of the elderly population, in association with the adoption of risk habits, and the use of new immunosuppressive drugs in cancer treatment. Cancer is a general term used to refer to over 100 diseases that share an uncontrolled growth of cells, which tends to result in the invasion of neighboring tissues and organs. Cancer is the second leading cause of death worldwide, accounting for approximately $13 \%$ of the total or about eight million deaths annually. It is estimated that nearly 13 million new cancer cases arise each year, and that this figure will reach 17 million by the end of this decade ${ }^{(3)}$.

The behavior of the Trypanosoma cruzi human infection when immunodeficiency is present still requires clarification,

Corresponding author: Msc. Luciane d'Avila Rosenthal.

e-mail: lulurosenthal@hotmail.com

Received 5 June 2016

Accepted 26 August 2016 which necessitates further studies of this group of patients. The coexistence of $\mathrm{CD}$ and immune disorders has been reported worldwide, and may lead to an acute reactivation with parasitemia and severe clinical manifestations such as meningitis and meningoencephalitis ${ }^{(4)(5)}$.

Located in the South of Brazil, the State of Rio Grande do $\mathrm{Sul}$ (RS), especially its Southern region, is considered endemic for $\mathrm{CD}$; insect vectors have been found in rural homes as recently as the last decade. Because of the possible comorbidity of cancer and $\mathrm{CD}$ in endemic areas, the aim of this study was to investigate the prevalence of CD in patients treated at a Public Oncology Service in the City of Pelotas in Southern RS, an area thought to be endemic for this parasitic disease.

The target population consisted of individuals between 18 and 80 years of age who were treated at the Oncology Department of the University Hospital of the Federal University of Pelotas (HE/UFPel) and who underwent chemotherapy for a one-year period.

Serological evaluation was performed using the chemiluminescence microparticle immunoassay method and positive results on this test were confirmed by indirect immunofluorescence. Individuals were considered infected when anti-T. cruzi $\operatorname{IgG}$ antibodies were detected using both methodologies. Test results were referred to the Statistical and Medical Archive Department and made available to physicians and patients.

A sample size of 200 individuals was used. This $n$ was estimated from the number of patients who attended the Oncology Department of the University Hospital of UFPel over 
a one-year period, in association with $\mathrm{CD}$ prevalence in the region in recent years. Since patients from 22 municipalities are attended to by this oncology department, this study population was representative of patients in the City of Pelotas and Southern RS State, who are thought to be representative of this region.

To characterize the patients' social and epidemiological profile, they were interviewed regarding their age, gender, schooling, economic status, place of birth, childhood residence, living or having lived in wattle-and-daub/clay houses, type of present dwelling, and location/type of cancer, among other variables. A descriptive comparison was performed between the two study groups (seropositive individuals to $T$. cruzi-positive group and seronegative individuals to $T$. cruzi-negative group) for each variable by expressing values in frequency (observed value-n) and percentage (\%). A statistical comparison was performed using the Poisson regression with robust variance. Prevalence ratio (PR) and 95\% confidence intervals $\left(\mathrm{CI}_{95 \%}\right)$ were calculated. Statistical comparison between the type of cancer and the presence of anti-T. cruzi antibodies was performed using the chi-square test.

A total of 265 individuals were invited to participate in the study. Of these, 43 refused to participate and 12 were aged
$<18$ or $>80$ years. One sample was lost because of blood hemolysis. Samples could not be obtained from nine individuals, as they had laboratory test reference values below recommended levels. All respondents were monitored by the medical team of the Oncology Department of the University Hospital/UFPel.

Considering the profile of the 200 individuals who took part in the survey, $79 \%$ were aged 50 years or older, $59.5 \%$ were female, $35 \%$ had up to four years of schooling, $54.5 \%$ were married, and $73.5 \%$ had a family income of up to two times the minimum wage.

Individual analysis of the presence of anti-T. cruzi IgG antibodies revealed that ten individuals were positive for the infection, which represented a $5 \%$ prevalence rate. By comparing variables with respect to the proportion of positive individuals (Table 1), the following factors were identified as possibly associated with the presence of anti-T. cruzi IgG antibodies: age 60 years or older ( $\left.\mathrm{PR}=10.57, \mathrm{CI}_{95 \%} 1.36-82.26\right)$, up to four years of schooling $\left(\mathrm{PR}=4.33, \mathrm{CI}_{95 \%} 1.16-16.24\right)$, having lived in a wattle-and-daub/clay house $\left(\mathrm{PR}=8.86, \mathrm{CI}_{95 \%}, 1.95-40.16\right)$, and having spent their childhood in the municipality of Canguçu (RS) ( $\mathrm{PR}=6.57, \mathrm{CI}_{95 \%} 1.95-22.11$ ).

As for the type of cancer in T. cruzi seropositive patients, $30 \%$ had proState tumors, $20 \%$ had stomach tumors, and the

TABLE 1

Analysis of sociodemographic factors of individuals with cancer who were seropositive for anti-Trypanosoma cruzi antibodies in an endemic area for Chagas disease in Southern Brazil.

\begin{tabular}{|c|c|c|c|c|}
\hline Variables & $\frac{\text { Total }}{\text { n (\%) }}$ & $\frac{T . \text { cruzi }+}{\text { n }(\%)}$ & PR & $\mathbf{C I}_{95 \%}$ \\
\hline \multicolumn{5}{|l|}{ Age group (years) } \\
\hline $60-80$ & $92(46.0)$ & $9(9.8)$ & 10.57 & $(1.36-82.26)$ \\
\hline \multicolumn{5}{|l|}{ Gender } \\
\hline female & $119(59.5)$ & $4(3.7)$ & 1 & - \\
\hline \multicolumn{5}{|l|}{ Years of schooling } \\
\hline$\leq 4$ years & $70(35.0)$ & $7(10.0)$ & 4.33 & $(1.16-16.24)$ \\
\hline$\geq 5$ years & $130(65.0)$ & $3(2.3)$ & 1 & - \\
\hline \multicolumn{5}{|l|}{ Fixed family income* } \\
\hline$\leq 2$ times the $\mathrm{MW}$ & $147(73.5)$ & $10(6.8)$ & - & - \\
\hline yes & $135(67.5)$ & $10(7.4)$ & - & - \\
\hline \multicolumn{5}{|c|}{ Have you ever lived in a wattle-and-daub/clay house } \\
\hline no & $93(68.9)$ & $2(2.2)$ & 1 & - \\
\hline yes & $42(31.1)$ & $8(19.0)$ & 8.86 & $(1.95-40.16)$ \\
\hline \multicolumn{5}{|c|}{ Where they had spent their childhood } \\
\hline Canguçu & $37(18.5)$ & $6(16.2)$ & 6.57 & $(1.95-22.11)$ \\
\hline others & $162(81.5)$ & $4(2.5)$ & 1 & - \\
\hline
\end{tabular}

T.: Trypanosoma; PR: prevalence ratio; $\mathbf{C I}_{95 \%}$ : 95\% confidence interval; MW: minimum wage *Brazilian MW = R \$ 880.00 (about 240.00 USD in March/2016. ** It was not possible to obtain estimates because of the occurrence of zero values. 
remaining $50 \%$ of cases comprised colon, cervix, non-Hodgkin's lymphoma, lung, and kidney cancers. There were no statistically significant differences between the type of cancer and the presence of anti-T. cruzi antibodies ( $\mathrm{p}$-value $=0.89$ ).

The $5 \%$ prevalence of $T$. cruzi found in this study was identical to that reported by Stauffert ${ }^{(6)}$ upon investigating T. cruzi/human immunodeficiency virus (HIV) co-infection in Southern Brazil. The results of that study indicated a risk of reactivation of the disease in HIV-positive patients, especially during periods of low cluster of differentiation 4 (CD4) T-cell count and high viral load. The viremia increase was the only statistically significant variable, resulting in a sevenfold increase in the likelihood of $T$. cruzi occurrence.

However, more recent $\mathrm{CD}$ seroprevalence data from the municipality of Pelotas have shown lower serum levels of anti-T. cruzi IgG antibodies in the general population, amounting to $2.7 \%$ in rural area residents ${ }^{(7)}$. In addition, a Brazilian CD seroprevalence survey $(2001-2008)^{(8)}$, reported a positivity rate of only $0.1 \%$. However, it should be noted that the above study evaluated children under 5 years of age, for whom coexistence with insect vectors in dwellings was much lower than that found in previous decades. Thus, the population of that study differed from the target population in the present research, in which $79 \%$ of the patients were 50 years or older, including some that had probably lived with triatomine infestation in their homes in the past.

According to the results of this study, $80 \%$ of the individuals with anti- $T$. cruzi antibodies had lived in wattle-and-daub/clay houses, which are considered a risk factor for the presence of vectors in the home environment, since these materials facilitate the development of cracks in the walls, which serve as lodging and reproduction sites for triatomines ${ }^{(9)}$.

The present study found that many T. cruzi-positive individuals had spent their childhood in the municipality of Canguçu (RS) $(60 \%)$, which is a risk factor for the presence of hemoflagellates. This fact is supported by the results of a study by Priotto et al. ${ }^{(10)}$ who, upon evaluating 22 municipalities in Southern RS, found the greatest triatomine catches in rural areas of the municipality of Canguçu in 2008-2009 and 2010-2011. This finding is also in agreement with the results of studies performed in the past decades $^{(11)}$, in which the municipalities in Southern RS with the highest number of triatomine catches were Canguçu, Piratini, Santana da Boa Vista, and Pinheiro Machado. It must also be noted that these municipalities, which are geographically very close, had been considered endemic for CD and showed high dwelling infestation levels by $T$. infestans in previous decades. Therefore, seropositive patients from these municipalities may have been infected via vectors 30 or 40 years ago.

All seropositive individuals earned up to two times the minimum wage and $70 \%$ of positive cases had up to four years of schooling. This finding is in agreement with others reports in the literature, which indicated that $\mathrm{CD}$ carriers generally belong to low socioeconomic and cultural classes that have been excluded by poverty and disease, having little power to make demands and virtually no political visibility ${ }^{(12)}$.
In the 1980s and early 1990s, it was shown that infected individuals with severely compromised immune systems, such as cancer patients, transplant recipients, and HIV-positive patients, were at risk for $\mathrm{CD}$ reactivation ${ }^{(13)}$. This study did not aim to follow positive individuals for a longer period to check for eventual CD reactivations. However, when they were clinically assessed by their doctors (both patients and doctors were aware of test positivity), they did not show any clinical sign that could be attributed to disease reactivation, and cancer remained a treatment priority. It must be noted that immunocompromised individuals with $\mathrm{CD}$ were observed for possible disorders related to the presence of the parasite, aiming to provide faster and more efficient treatment in case of reactivation, since $\mathrm{CD}$ can present unusually severe clinical manifestations in immunocompromised patients, such as meningitis and meningoencephalitis ${ }^{(5)}$.

In recent decades, cancer has gained the status of a global public health hazard and the World Health Organization has estimated 27 million new cases and 17 million cancer deaths in the year $2030^{(14)}$. Since cancer can coexist with CD, $\mathrm{CD}$ reactivation cases have been reported in patients with hematologic malignancies, such as leukemias and lymphomas, who were undergoing cancer chemotherapy and corticosteroid treatment ${ }^{(15)}$. The most frequent malignancies in CD seropositive patients in this study were proState and stomach cancer, and reactivation events were not diagnosed in these patients. However, it should be borne in mind that the abovementioned research investigations were not prevalence studies, but rather tried to describe cases of $\mathrm{CD}$ reactivation that are perhaps more common in patients with hematological malignancies, which directly affect immune system cells.

This is the first report demonstrating the prevalence of CD in cancer patients. The rate of seropositive $T$. cruzi individuals in the population with cancer was considerable, and eventual disease reactivation in these patients could result in severe symptoms. Therefore, serological checks for T. cruzi in cancer patients are suggested, especially in those who are 50 years of age or older, who live or have lived in wattle-and-daub/clay houses, and who come from endemic areas for Chagas disease in Brazil and other Latin American countries.

\section{Ethical considerations}

The study was approved by the Ethics Committee of the Medicine School of UFPel. The study involved the use of a questionnaire and the collection of venous blood to detect anti-T. cruzi immunoglobulin $\mathrm{G}$ ( $\mathrm{IgG}$ ) antibodies. After the questionnaire was answered, blood samples were collected.

\section{Conflict of Interest}

The authors declare that there is no conflict of interests.

\section{Financial Support}

Provided by Programa de Apoio à Pós-Graduação (PROAP), Coordenação de Aperfeiçoamento de Pessoal de Nivel Superior (CAPES), Brasília, DF, Brazil. 


\section{REFERENCES}

1. Rassi Jr A, Rassi A, Marin-Neto JA. Chagas disease. The Lancet 2010; 375:1388-1402.

2. Sommese L, Fiorito C, Napoli C. The relationship between Chagas disease and immunosuppressive therapy. Blood Transfus 2014; 12 (suppl I):s381-s382.

3. Goulart FAA. Doenças crônicas não transmissíveis: estratégias de controle e desafios e para os sistemas de saúde. Brasília: PanAmerican Health Organization (PAHO); 2011. 66p. Cited 2015 April 10. Available at: http://apsredes.org/site2012/wp-content/ uploads/2012/06/Condicoes-Cronicas_flavio1.pdf.

4. Bisio M, Altcheh J, Lattner J, Moscatelli G, Fink V, Burgos JM, et al. Benznidazole treatment of chagasic encephalitis in pregnant woman with AIDS. Emerg Infect Dis 2013; 19:1490-1492.

5. Salvador F, Sánchez-Montalvá A, Valerio L, Serre N, Roure $\mathrm{S}$, Treviño $\mathrm{B}$, et al. Immunosuppression and Chagas disease; experience from a non-endemic country. Clin Microbiol Infect $2015 ; 21: 854-860$.

6. Stauffert D. Coinfecção Trypanosoma cruzi/HIV, no extremo sul do Brasil. Tese Doutorado. Pelotas: Universidade Federal de Pelotas; 2015. 68p.

7. Araújo AC, Rodrigues SC, Rezende AFS, Villela MM, Borsuk S. Soroprevalência de infecção humana por Trypanosoma cruzi em uma área rural do sul do Brasil. Rev Patol Trop 2015; 44:423-431.
8. Ostermayer AL, Passos ADC, Silveira AC, Ferreira AW, Macedo V, Prata AR. O inquérito nacional de soroprevalência de avaliação do controle da doença de Chagas no Brasil (2001-2008). Rev Soc Bras Med Trop 2011; 44 (supl 2):108-121.

9. Saunders M, Small A, Dedicoat M, Roberts L. The development and validation of a risk score for household infestation by Triatoma infestans, a Bolivian vector of Chagas disease. Trans R Soc Trop Med Hyg 2012; 106:677-682.

10. Priotto MCM, Santos CV, Mello F, Ferraz ML, Villela MM. Aspectos da vigilância entomológica da doença de Chagas no sul do Rio Grande do Sul, Brasil. Rev Patol Trop 2014; 43:228-238.

11. Baruffa G, Alcantara Filho A. Inquérito sorológico e entomológico da infecção pelo T. cruzi na região Sul do Rio Grande do Sul, Brasil. Ann Soc Belg Med Trop 1985; 65 (supl 1):171-179.

12. Dias JPC. Doença de Chagas, ambiente, participação e Estado. Cad Saude Publica 2001; 17 (supl):165-169.

13. Lattes R, Linares L, Radisic M. Emerging parasitic infections in transplantation. Curr Infect Dis Rep 2012; 14:642-649.

14. World Health Organization (WHO). International Agency for Research on Cancer (IARC)/Research I-IAfC. Cited 2015 June 02. Available at: http://www.iarc.fr/2015.

15. Ferreira MS, Borges AS. Some aspects of protozoan infections in immunocompromised patients - a review. Mem Inst Oswaldo Cruz 2002; 97:443-457. 